\title{
Apples and Oranges: A Framework to Explore the Practiced Pedagogy in Experiential Learning
}

\author{
http://dx.doi.org/10.3991/ijep.v5i3.4479 \\ G.P. Banky and A.S. Blicblau \\ Swinburne University of Technology, Melbourne, Australia
}

\begin{abstract}
Experimental learning, traditionally conducted in on-campus laboratory venues, is the cornerstone of science and engineering education. To satisfy online student and accreditation requirements, the common practice has been to offer equivalent remote and/or simulated laboratory experiments in lieu of the ones delivered, face-to-face, on campus. The current implementations of both remote and simulated laboratories tend to be specified with a focus on technical characteristics, instead of pedagogical requirements. This work attempts to redress this situation by detailing a framework for the investigation of quality teaching and learning in existing and proposed experimental educational environments. For the tertiary education sector, involved with technical or scientific training, a tool capable of comparatively assessing the pedagogical limitations of laboratory venues is an important aid during the planning, designing and evaluating stages of face-to-face and online environments that facilitate student experimentation. Providing quality experimental learning venues has been identified as one of the distance-education providers' greatest challenges.
\end{abstract}

Index Terms-experimental learning, kikan-shido, venue affordace.

\section{INTRODUCTION}

The recent growth of the digital economy and the rapid development of internet communication technologies have promised improved online education and training [1]. Furthermore, extra pressures exist on education providers to be globally competitive in their tertiary education offerings by improving the quality of their internet-based delivery with the incorporation of new technologies.

Attempts to address the engineering skills shortage in Australia by increasing graduate numbers [2], while dealing with budgeting pressures with academic staff cutbacks, have challenged the higher education institutions to migrate a number of their courses to online platforms. This includes courses in science, technology, engineering and mathematics (STEM) education that involve experimental learning in laboratory venues [3]. In engineering, as in all the STEM disciplines, laboratory work targets four broad educational objectives: conceptual understanding, design skills, social skills and professional skills [4]

The provision of quality experimental learning has been identified as one of the distance-education providers' greatest challenges $[5,6]$. We use the term "affordance" how an object, or an environment, impacts on the actions of its user(s) and is attributed to Gibson [7]. Norman [8] argued that while affordances facilitate use, constraints impede potential uses. Hence, affordances must be context specific.

For the tertiary education sector providing technical or scientific training, a framework helping to identify venue affordances will be beneficial during the planning, designing and evaluating stages of face-to-face and online (or cyber) environments that facilitate student experimentation. Our proposed framework focuses only on pedagogical (or learning and teaching) affordances of experimental learning venues for engineering undergraduate courses.

\section{Methodology}

The underlying methodology utilized in our work is based on the assumption that if: affordances impact on activity then activity patterns reflect on a venue's affordances, hence on learning outcomes. Some affordances may cause learning outcomes that might not be acceptable to engineering course accreditation bodies such as Engineers Australia (http://www.engineersaustralia.org.au); perhaps resulting in the professional course(s) not being reaccredited and ultimately not being offered.

The foundation of the framework which we have developed, involves the analysis of video data to identify the occurrences of "kikan-shido" (a Japanese term meaning 'between desks instruction' [9]) events which are detailed, in Table 1. The videos were recorded by a number of participants, who wore "video glasses". Additionally, a wide angle fixed video camera documented the activities in the venue, thereby augmenting the individual recordings.

The processing of the collected data utilised a threelayered interpretive model for media-rich research into social interaction, attributed to Wortham and Derry [10]. This model ensures a traceable path from the analysed data, through any intervening depiction(s), back to the recorded data. One of the benefits of this technique is an implied link between the various data forms and the raw data. Additionally, video recordings of the sessions resulted in permanent records that permitted a researcher and/or any other expert(s) and/or interested parties to repeatedly review the affordances depicted in the video recordings, facilitating coding or recoding anytime [11].

As seen in Figure 1, the analysis of the video recordings resulted in a summary of the identified kikan-shido activities between:

- student and student (or peer-to-peer) and;

- student and demonstrator. 
TABLE I.

KIKAN-SHIDO ACTIVITY DEFINITIONS [12; P.77]

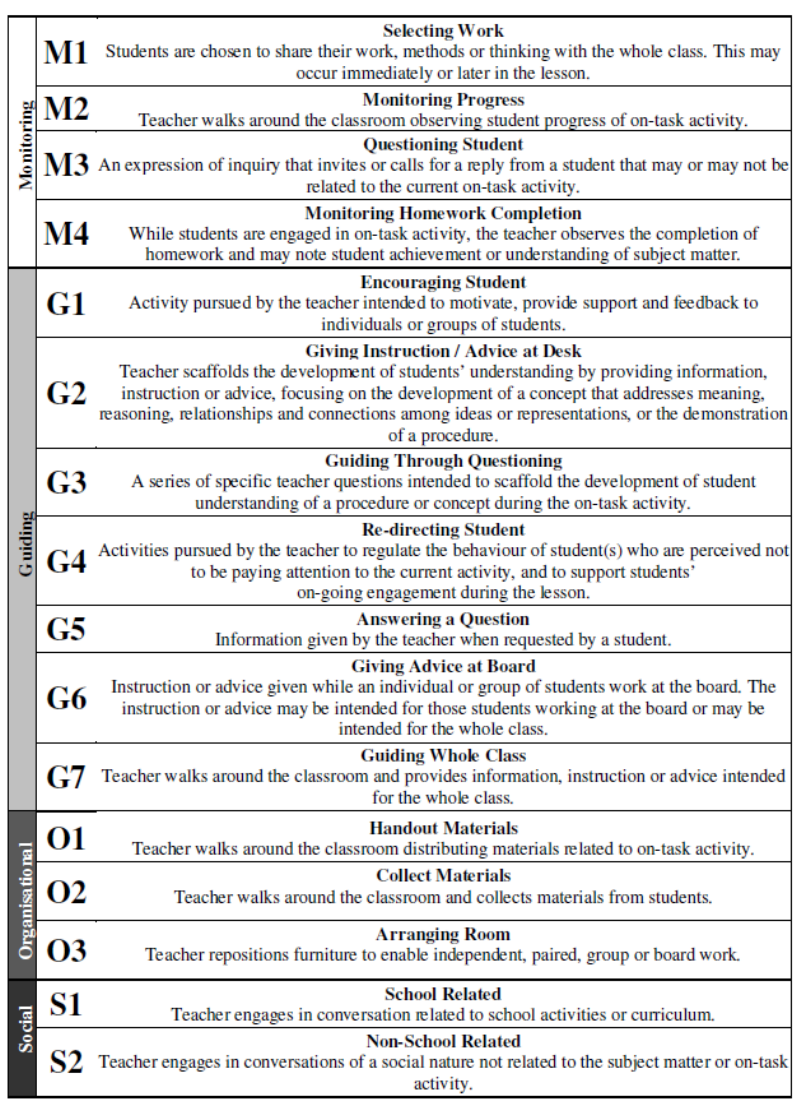

\section{THE FRAMEWORK}

The proposed framework for the investigation of quality teaching and learning in existing and proposed experimental educational environments has the following structure:

- Selection of the experimental learning venue for investigation.

- Collection of data by videoing student-student and student-demonstrator interactions.

- Analysis of recordings for kikan-shido events listed in Table I.

- Summaries of the recordings' analysis by creating binary tables as shown in Figure 1 and Figure 2.

- Mapping of identified kikan-shido events to venue communication affordances shown in Figure 3.

- Deduction of pedagogy supported by venue.

\section{CASE STUdy}

In this section we provide details of a case study that was conducted at Swinburne University of Technology, Melbourne, Australia, involving electrical engineering undergraduate students. The venue is shown in Figure 1.

In our study 96 students were involved in "real" and simulated experiments. The participants self-selected into groups of two, with eight to ten such groups and two academic demonstrators per session. In their groups of two, the learners were asked to design, simulate and test a specified transistor-based amplifier circuit and then repeat the

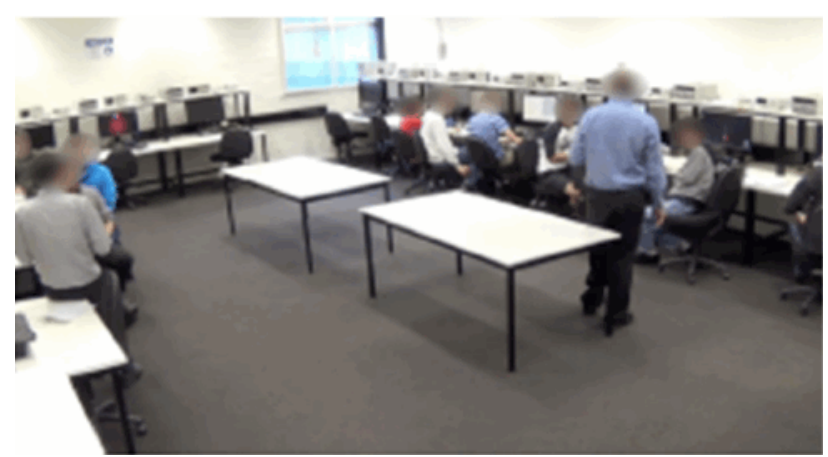

Figure 1. De-identified photo of experimental learning space, which was investigated in the case study [13]

process using real components. In their post-experiment group-written reports the students were asked to compare and discuss the performance of their simulated and their subsequent physical-component realizations. The pedagogy observed in this case study was "student-centered learning".

Commercially available video glasses worn by students, together with a fixed wide-angle camera were employed to monitor and record class activities. The video analysis tool, Studiocode (http://www.studiocodegroup.com) was used to keep track of the identified kikan-shido events, which occurred during the recorded laboratory sessions. The study resulted in 34 student and 17 demonstrator recordings all of which were collected for analysis.

For the students, the original set of 16 kikan-shido events (shown in Table I) were expanded to 32, thus enabling the identification of both student-student and student-demonstrator interactions for the observed participants.

Over 20 hours of recordings were collected with the video glasses and the fixed wide-angle video camera.

The collected data was de-identified, as mandated in the ethics approval and summarized in the following ways:

- histograms of time taken for each kikan-shido event in seconds and as a percentage of the length of each recording;

- a binary indicator if a kikan-shido event occurred during the recording.

\section{DISCUSSION}

Following the review of analyzed data we determined that a time-based tabulation reflected more on:

- student abilities and learning preferences;

- demonstrator teaching styles; and/or

- the type of laboratory experiment performed.

Consequently, the research team resolved that summaries of binary tabulations of the identified kikan-shido events did indeed reflect on the affordances of the investigated experimental learning venues.

Therefore, the analysis summaries, shown in Figure 2 and Figure 3, simply documented "if" a kikan-shido event occurred during the recorded sessions. The events, which were not identified, were also logged by default. Although, the identification of an event was noted numerically with the number " 1 "; subsequent identifications of the same event for that recording were disregarded. 
SHORT PAPER

APPLES AND ORANGES: A FRAMEWORK TO EXPLORE THE PRACTICED PEDAGOGY IN EXPERIENTIAL LEARNING

SUT

\begin{tabular}{|c|c|c|}
\hline G1-ENCOURAGE STUDENT & 0 & $0.00 \%$ \\
\hline G2-GIVING INSTRUCTION & 1 & $2.94 \%$ \\
\hline G3-GUIDING BY QUESTIONING & 0 & $0.00 \%$ \\
\hline G4-REDIRECTING STUDENT & 0 & $0.00 \%$ \\
\hline G5-ANSWERING QUESTION & 0 & $0.00 \%$ \\
\hline G6-ADVICE ON BOARD & 0 & $0.00 \%$ \\
\hline G7-GUIDE WHOLE CLASS & 0 & $0.00 \%$ \\
\hline GS1-ENCOURAGE STUDENT & 3 & $8.82 \%$ \\
\hline GS2-GIVING INSTRUCTION & 22 & $64.71 \%$ \\
\hline GS3-GUIDING BY QUESTIONING & 20 & $58.82 \%$ \\
\hline GS4-REDIRECTING STUDENT & 13 & $38.24 \%$ \\
\hline GS5-ANSWERING QUESTION & 20 & $58.82 \%$ \\
\hline GS6-ADVICE ON BOARD & 0 & $0.00 \%$ \\
\hline GS7-GUIDE WHOLE CLASS & 0 & $0.00 \%$ \\
\hline M1-SELECTING WORK & 0 & $0.00 \%$ \\
\hline M2-MONITOR PROGRESS & 0 & $0.00 \%$ \\
\hline M3-QUESTION STUDENT & 0 & $0.00 \%$ \\
\hline M4-MONITOR STUDENT & 0 & $0.00 \%$ \\
\hline MS1-SELECTING WORK & 0 & $0.00 \%$ \\
\hline MS2-MONITOR PROGRESS & 2 & $5.88 \%$ \\
\hline MS3-QUESTION STUDENT & 23 & $67.65 \%$ \\
\hline MS4-MONITOR STUDENT & 0 & $0.00 \%$ \\
\hline O1-HANDOUT MATERIALS & 0 & $0.00 \%$ \\
\hline O2-COLLECT MATERIALS & 0 & $0.00 \%$ \\
\hline O3-ARRANGING ROOM & 0 & $0.00 \%$ \\
\hline OS1-HANDOUT MATERIALS & 0 & $0.00 \%$ \\
\hline OS2-COLLECT MATERIALS & 0 & $0.00 \%$ \\
\hline OS3-ARRANGING ROOM & 0 & $0.00 \%$ \\
\hline S1-SCHOOL RELATED & 0 & $0.00 \%$ \\
\hline S2-NON-SCHOOL RELATED & 0 & $0.00 \%$ \\
\hline SS1-SCHOOL RELATED & 5 & $14.71 \%$ \\
\hline SS2-NON-SCHOOL RELATED & 0 & $0.00 \%$ \\
\hline
\end{tabular}

Figure 2. Typical summary of identified student kikan-shido events in the recorded videos

$\underline{\text { SUT }}$

\section{(17) Total Weighted}

$\begin{array}{lrr}\text { G1-ENCOURAGE STUDENT } & 1 & 5.88 \% \\ \text { G2-GIVING INSTRUCTION } & 15 & 88.24 \% \\ \text { G3-GUIDING BY QUESTIONING } & 6 & 35.29 \% \\ \text { G4-REDIRECTING STUDENT } & 7 & 41.18 \% \\ \text { G5-ANSWERING QUESTION } & 13 & 76.47 \% \\ \text { G6-ADVICE ON BOARD } & 1 & 5.88 \% \\ \text { G7-GUIDE WHOLE CLASS } & 5 & 29.41 \% \\ \text { M1-SELECTING WORK } & 0 & 0.00 \% \\ \text { M2-MONITOR PROGRESS } & 2 & 11.76 \% \\ \text { M3-QUESTION STUDENT } & 3 & 17.65 \% \\ \text { M4-MONITOR STUDENT } & 4 & 23.53 \% \\ \text { O1-HANDOUT MATERIALS } & 3 & 17.65 \% \\ \text { O2-COLLECT MATERIALS } & 3 & 17.65 \% \\ \text { O3-ARRANGING ROOM } & 0 & 0.00 \% \\ \text { S1-SCHOOL RELATED } & 1 & 5.88 \% \\ \text { S2-NON-SCHOOL RELATED } & 0 & 0.00 \%\end{array}$

Figure 3. Typical summary of identified demonstrator kikan-shido events in the recorded videos

\begin{tabular}{|c|c|c|c|c|}
\hline & $\begin{array}{c}\text { One } \\
\rightarrow \\
\text { One }\end{array}$ & $\begin{array}{c}\text { One } \\
\rightarrow \\
\text { Many }\end{array}$ & $\begin{array}{c}\text { Many } \\
\rightarrow \\
\text { One }\end{array}$ & $\begin{array}{c}\text { Many } \\
\rightarrow \\
\text { Many }\end{array}$ \\
\hline Audible & $\begin{array}{l}\text { G1, } \\
\text { G2, } \\
\text { G3, } \\
\text { G4, } \\
\text { G5. }\end{array}$ & $\begin{array}{l}\text { M1, } \\
\text { M3, } \\
\text { M4, } \\
\text { G1, } \\
\text { O1. }\end{array}$ & G6. & $\begin{array}{l}\text { G7, } \\
\text { S1, } \\
\text { S2. }\end{array}$ \\
\hline Visual & $\begin{array}{l}\text { G1, } \\
\text { G2, } \\
\text { G3, } \\
\text { G4, } \\
\text { G5. }\end{array}$ & $\begin{array}{l}\text { M1, } \\
\text { M3, } \\
\text { M4, } \\
\text { G1, } \\
\text { O1. }\end{array}$ & $\begin{array}{l}\text { M2, } \\
\text { G6. }\end{array}$ & $\begin{array}{l}\text { G7, } \\
\text { S1, } \\
\text { S2. }\end{array}$ \\
\hline Gesturing & $\begin{array}{l}\text { G1, } \\
\text { G2, } \\
\text { G3, } \\
\text { G4, } \\
\text { G5. }\end{array}$ & G1. & G6. & G7. \\
\hline
\end{tabular}

Figure 4. Mapping kikan-shido events to venue communication affordances

As observed from the percentage values in the "Weighted" columns of Figure 2 and Figure 3 some kikan-shido events were detectable for nearly all participants. The higher the value of this percentage, the greater is the need to ensure that the affordance of a chosen faceto-face or cyber venue, in which the experiment is to be performed, facilitates such kikan-shido events.

In order to mimic the pedagogy that could be practiced during a laboratory experiment, the communication affordances (which are required for face-to-face and online delivery) have been mapped, in Figure 4, to all the kikanshido events that may occur. This mapping identified the communication affordances that were necessary to facilitate each event.

\section{CONCLUSION}

The identification of student-student and studentdemonstrator kikan-shido events confirmed the venue's affordances as far as those events were concerned. This in turn indicates the pedagogy that the venue facilitates. We can only establish "that something is positively the case, never the reverse" [14; p.30]. Events that were not identified may indicate a potential shortfall in venue affordances (by not supporting those events), or that there was no need for these in the context of the experimental learning, or both. Therefore, it is not possible to conclude absolutely that no other venue affordances are required "any more than ... anyone could prove definitively, to use an age-old example, that "there is not a teapot in orbit around Mars"” [14; p.30].

With reference to Figure 4, we can conclude that the real-time online implementation of the three communication modes (namely audible, visual and gesturing) can fully 
facilitate the mimicking of face-to-face experimental pedagogy (in the form of supporting all the kikan-shido events) for off-campus students.

The framework applied in this investigation ensured "repeatability" of both data collection and subsequent analysis - a highly desirable feature, in case verifications of the analysis were attempted by other researcher(s) and/or any other expert(s) and/or interested parties.

Furthermore, the data collected using video recordings were free from any participants' personal bias, contrasting previously reported investigations, in which data collection was obtained from student/staff experience surveys, focus groups, participants' reflective journals, formal report marks, marks obtained for pre-event and post-event testing [15].

\section{ACKNOWLEDGMENT}

The authors would like to acknowledge the contributions received from the following academic colleagues: Dr P. Egodawatta (Queensland University of Technology, Brisbane, Australia); Dr F. Anwar and A/Prof H. Vuthaluru (Curtin University, Perth, Australia); together with Dr H. Neoh, D. Richards and M. Vcelka (Swinburne University of Technology, Melbourne, Australia).

\section{REFERENCES}

[1] M. Bell, D. Bush, P. Nicholson, D. O'Brien, and T. Tran, "Universities Online: A survey of online education in Australia," Department of Education, Science and Training, Canberra, ACTMarch, 20022002.

[2] C. Back, G. Marshall, A. Gallacher, B. McKenzie, L. Rhiannon, and S. Boyce, "The shortage of engineering and related skills," The Senate, Commonwealth of Australia, Canberra, ACT2012.

[3] J. V. Nickerson, J. E. Corter, S. K. Esche, and C. Chassapis, "A model for evaluating the effectiveness of remote engineering laboratories and simulations in education.," Computers and Education, vol. 49, pp. 708-725, 2007. http://dx.doi.org/10.1016/j.compedu.2005.11.019

[4] J. Lang, " Comparative Study of Hands-on and Remote Physics Labs for First Year University Level Physics Students," Transformative Dialogues: Teaching \& Learning Journal, vol. 6, August 1, 20122012.

[5] S. C. Sivakumar, W. Robertson, M. Artimy, and N. Aslam, "A web-based remote interactive laboratory for Internetworking education," IEEE Transactions on Education, vol. 48, pp. 586598, November, 20052005.

[6] J. B. Arbaugh and R. Benbunan-Fich, "Contextual Factors That Influence ALN Effectiveness," in Learning together online: research on asynchronous learning, S. R. Hiltz and R. Goldman, Eds., ed Mahwah, NJ: Lawrence Erlbaum Associates, Inc., 2005.

[7] J. J. Gibson, "The theory of affordances," in Perceiving, acting, and knowing: Toward an ecological psychology, R. Shaw and J. Bransford, Eds., ed Hillsdale, NJ: Lawrence Erlbaum Associates, 1977.

[8] D. A. Norman, The Design of Everyday Things. New York, NY.: Doubleday, 1990.

[9] D. J. Clarke, "CHAPTER TWO: The LPS Research Design," in Mathematics Classrooms in Twelve Countries: The Insider's Perspective, D. J. Clarke, C. Keitel, and Y. Shimizu, Eds., ed Rotterdam, The Netherlands: Sense Publishers, 2006, pp. 15-36.

[10] D. W. Wortham and S. J. Derry, "Ways of Working: A Threetiered Interpretive Model for Video Research," in 7th International Conference on Learning Sciences, Bloomington, IN, 2006.

[11] J. Fraenkel and N. Wallen, How to Design and Evaluate Research in Education, 6th. ed. New York, NY: McGraw-Hill, 2006.

[12] K. O'Keefe, L. H. Xu, and D. J. Clarke, "Chapter Four: KikanShido: Between Desks Instruction," in Making Connections: Comparing Mathematics Classrooms Around the World, D. J. Clarke, J. Emanuellson, E. Jablonka, and I. A. C. Mok, Eds., ed Rotterdam, The Netherlands: Sense Publishers, 2006.

[13] M. Vcelka and G. P. Banky, "Pictures and words: Data collection proposal to investigate the affordances of current experiential learning environments," presented at the 2014 Australasian Association for Engineering Education Conference (AAEE2014), Wellington, New Zealand, 2014.

[14] S. Greenfield, Mind Change. London, UK: Ebury Publishing, 2014.

[15] G. P. Banky, A. S. Blicblau, P. Egodawatta, H. Vuthuluru, and M. Vcelka, "Development of a research tool to investigate pedagogical affordances of engineering students' experimental learning venues," Australian Government Office for Learning and Teaching (OLT), Sydney, NSW2015.

\section{AUTHORS}

G. P. Banky is a Senior Lecturer with the Faculty of Science, Engineering and Technology, Swinburne University of Technology, Hawthorn, Victoria, Australia, 3122 (e-mail: gbanky@swin.edu.au).

A. S. Blicblau is a Senior Lecturer with the Faculty of Science, Engineering and Technology, Swinburne University of Technology, Hawthorn, Victoria, Australia, 3122 (e-mail: ablicblau@swin.edu.au).

This work was supported by the Australian Government Office for Learning and Teaching (OLT) Seed Grant SD13-1322; and in-kind by the Studiocode Business Group, Warriewood, NSW, Australia. The views expressed do not necessarily reflect the views of the OLT.

Submitted, February, 19, 2015. Published as resubmitted by the authors on June, 25, 2015. 